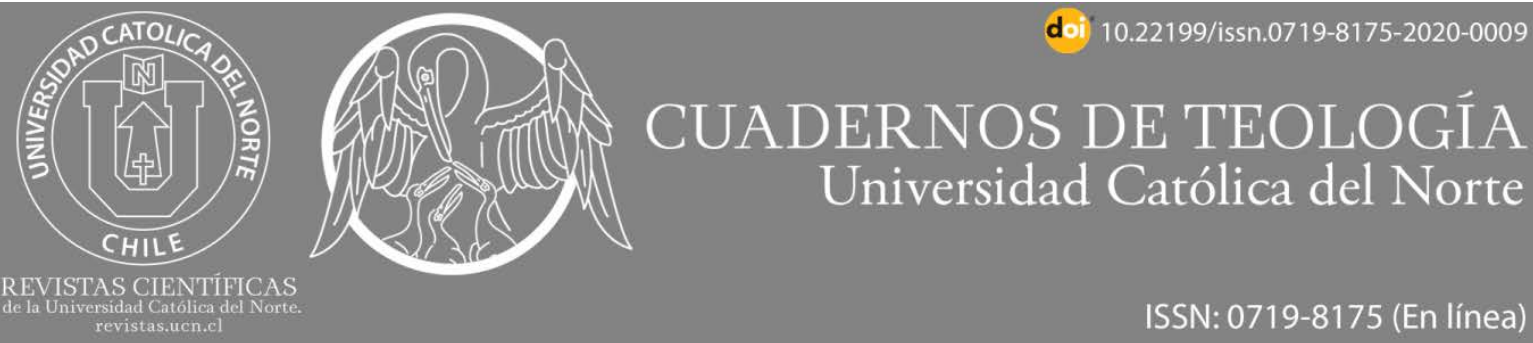

\title{
El principio de creatividad, en tiempo de la COVID-19 en la actividad del ser humano
}

\section{The principle of creativity, in time of COVID-19 in the activity of the human being}

\author{
Mario Hernando Vergara Amaya' (1) orcid.org/0000-0003-3721-2595

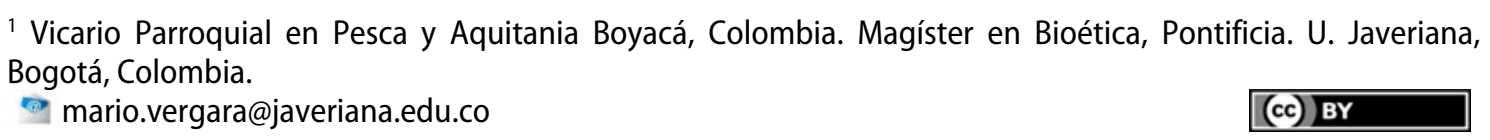

\section{Resumen:}

Se intenta relacionar los conceptos del principio de creatividad con la actividad de cada ser humano, a partir de los postulados teológicos originados de la Constitución Gaudium et Spes y la Laudato Si'. También tendrá como referente, el artículo Creatividad. Una revisión descriptiva sobre nuestra capacidad de invención e innovación de Veronika Díaz Abrahan y Nadia Justel. Estos textos, muestran una apuesta orientadora para la construcción de un discurso creyente, sobre cómo se puede utilizar el principio de la creatividad como paradigma para una mejor calidad de vida. Especialmente, en un contexto como el de la pandemia COVID-19, que ha originado diversos escenarios de vida del ser humano y de sus actividades.

Palabras Clave: Imaginación constructiva; Documentos vaticanos; Pandemia; Escenarios de vida; Coronavirus.

\section{Abstract:}

An attempt is made to relate the concepts of the principle of creativity with the activity of each human being, based on the theological postulates originating from the Constitution Gaudium et Spes and Laudato Si'. It will also have as a reference, the article Creativity. A descriptive review on our capacity for invention and innovation from Veronika Díaz Abrahan and Nadia Justel. These texts, show a guiding bet for the construction of a believing discourse, on how the principle of creativity can be used as a paradigm for a better quality of life. Especially in a context such as the COVID-19 pandemic, which has originated various life scenarios for human beings and their activities.

Keywords: Constructive imagination; Vatican documents; Pandemic; Life scenarios; Coronavirus. 


\section{Introducción}

Esta apuesta analítica parte de una perspectiva teológica que pretende aportar nuevos elementos que constituyan un camino interdisciplinar, principalmente, al tener un acercamiento a la Bioética Personalista. Esta última se ocupa de enfrentar problemas nuevos en la realidad de cada ser humano y que, por lo mismo, ofrece -en su deseo de ser puente de saberes- al don de la vida y a su dignidad una construcción ordenada de la misma al ser humano en su diario vivir individual y colectivo; para sopesar lo impuesto por la autoridad local como medida de prevención por la consecuencia originada por la pandemia COVID-19, cuyas imágenes reflejan un panorama devastador en lo que comporta cada contexto y cultura de la vida de cada ser humano.

De manera que, como propuesta y desafío bioético, se valore y acoja el gran trabajo que se hace con la educación, ya que ha sabido acoger principios teóricos ofrecidos por las ciencias que, por naturaleza, han sabido ayudar al ser humano; pero que ante escenarios vividos por la pandemia COVID-19, reclaman un estímulo a la actividad que hoy puede hacer parte de ese proceso de vida que investiga, crea, propone, y desarrolla ideas para una pronta solución a tan compleja situación, de la cual todos hacemos parte y en la cual tenemos una gran responsabilidad. Que cada uno, bajo los elementos de juicio éticos y morales en la actividad que corresponda realizar, ofrezcamos espacios de vida, frutos de nuestra creatividad.

\section{La actividad en la Gaudium et Spes}

En un contexto como la pandemia generada por el SARS- CoV- $2^{1}$, que acompaña el proceso histórico de la humanidad, la Constitución Dogmática Gaudium Et Spes encontrada en el Concilio Vaticano II, se convierte en eje importante sobre el cual gira la vida de la Iglesia. Pues concede la oportunidad de abordarla en su integridad con el objetivo de apropiarnos de su riqueza y perspectivas en el mundo de hoy. Ya que, obedece a un proyecto magisterial, en cuanto que pone de manifiesto las realidades que está enfrentando el ser humano queriendo Ilamarlo: "...la familia humana que poco a poco ha llegado a reconocerse y constituirse como una sola comunidad mundial" (Paulo VI, 1965b, 33), argumento que motiva a que, como Iglesia, ofrezca respuestas claras sobre su pensamiento acerca del hombre, y que sus recomendaciones edifiquen una sociedad moderna, con el principio de creatividad ejercido en la actividad que cada ser humano puede realizar, escenario para la supervivencia de los seres humanos y de todo cuanto prevalece por el principio de la vida.

\footnotetext{
1 SARS- CoV-2. Virus que causa una enfermedad respiratoria llamada enfermedad por coronavirus de 2019 (COVID-19). El SARS-CoV-2 es un virus de la gran familia de los coronavirus, un tipo de virus que infecta a seres humanos y algunos animales. La infección por el SARS-CoV-2 en las personas se identificó por primera vez en 2019. Se piensa que este virus se transmite de una persona a otra en las gotitas que se dispersan cuando la persona infectada tose, estornuda o habla. Es posible que también se transmita por tocar una superficie con el virus y luego llevarse las manos a la boca, la nariz o los ojos. Hay estudios de investigación en curso sobre el tratamiento de la COVID-19 y la prevención de la infección por el SARS-CoV-2. También se llama coronavirus 2019-nCoV y coronavirus del síndrome respiratorio agudo grave de tipo 2.(Instituto Nacional del Cáncer, s.f, definición 1).
} 
De esta manera, el esfuerzo hecho por el Concilio a través de la Constitución Gaudium et Spes, da importantes claves hermenéuticas para entender el deseo de la Iglesia. Pues se lee una intención profunda de obediencia, en cuanto que reflexiona y motiva a profundizar un trabajo en favor de la vida, que históricamente recoge su contenido en una teología puesta al servicio de la humanidad. Retomando las raíces del cristianismo, expuestas en la Sagrada Escritura en Gen 1-2, donde en Dios encontramos su acto creador con el primer relato de la creación y con la prueba de la libertad en el paraíso (Biblia de Jerusalén, 1975, pp. 13-16), como en los grandes maestros de la cristiandad, exponentes de la enseñanza teológica, de la fe para los diversos contextos y culturas pertenecientes a un camino que conjuntamente por el tiempo se ha logrado vivir.

Con esta visión de conjunto, se pretende recoger la importancia de este documento para la sociedad actual, donde se hace evidente la impronta de que, en la actividad de cada ser humano desarrollada a través del tiempo, se valore y se motive al gozo del principio de creatividad, que para este artículo, puede ser entendido desde la postura de Veronika Díaz Abrahan1 y Nadia Justel (2019) como:

El campo de la creatividad resulta ser un área de difícil investigación, pero de capital interés para comprender y arrojar luz sobre la cognición humana, sobre el modo como resolvemos problemas que se presentan en la vida cotidiana y cómo hacemos uso de esta capacidad para fines recreativos, entre otros. (p. 45)

Originaria del ser humano dentro de la actividad que realizan en bien de la supervivencia de los mismos ya que, en los diversos contextos y culturas, la vida es un don que debe prevalecer bajo el peso de toda circunstancia. Y, desde la actividad que realiza el ser humano, se debe configurar el gran interés de salvaguardarla siempre utilizando el principio de la creatividad. Ahora, con base en el dato ofrecido por Gaudium et Spes se intentará un acercamiento a la Carta encíclica Laudato Si' (Francisco, 2015) ${ }^{2}$, ya que permite ampliar y desarrollar una reflexión en torno a la actividad propia del ser humano como un espacio para la creatividad de ideas que permiten una orientación al cuidado de la vida frente al escenario de la pandemia COVID-19.

\section{La actividad del ser humano como una aproximación de la Laudato Si’}

La Encíclica Laudato Si', sobre el cuidado de la casa común, cuya preocupación se convierte en un "... desafío urgente de proteger nuestra casa común incluye la preocupación de unir a toda la familia humana en la búsqueda de un desarrollo sostenible e integral, pues sabemos que las cosas pueden cambiar" (Francisco, 2015, art. 13). Como vemos, mantiene una coherencia interna fundamentada y orientada por la actividad que el ser humano puede ofrecer y que permite seguir. En primer lugar, la historia de la creación como la acción concreta de Dios y; en segundo lugar, de hombres y mujeres que, por su virtud relacionada con la fe, han sembrado en la historia una semilla donde la calidez de su mensaje y gran

\footnotetext{
${ }^{2}$ Carta Encíclica, sobre el cuidado de la casa común.
} 
enseñanza hace posible que hoy se realice un discurso creyente, sobre lo que hoy se convierte en desafío para todos: salvar la vida.

Este objetivo reserva un amplio espacio a la persona, por ser la directamente responsable del trabajo activo y creativo que se realiza para el cuidado de la vida; riqueza de temas Teológicos Filosóficos, Antropológicos, etc. Junto con las perspectivas bioéticas nuevas que han de ser profundizadas como método orientador para el cuidado de la vida dentro de la casa común; misterio inefable que abraza toda condición, que no excluye, sino que incluye la emergente situación por la cual atraviesa hoy la humanidad para la búsqueda científica de una solución.

De esta manera, se puede considerar que el tema de la actividad del ser humano, ocupa un lugar fundamental en la encíclica, pues el ofrecimiento, puesto en escena, de que el cuidado de la vida depende de la actividad que brinda el dato de la realidad científico y académico, pero también de la creatividad individual y colectiva. Es decir, de lo que cada uno, en los diversos contextos, posee para realizar o desarrollar, genera un punto de referencia en la identificación de posibles soluciones asociados con elementos de juicio creativo en el lenguaje de esperanza, fraternidad, solidaridad. De belleza en nuestra relación con el mundo y con los demás seres que poseen la vida. Entre otros, como un acto totalmente humano, potenciado por lo que la misma naturaleza hoy reclama, en su deseo de ser luz en lo que respecta a un aislamiento, a un autocuidado inteligente, a ser signos de esperanza, arquitectos ante el hecho reparador y capaces de ofrecer científica, académica y pedagógicamente el reinventar cada espacio y oportunidad de vida, que permita ocupar históricamente la razón de ser y estar en el mundo.

En conclusión, los argumentos ofrecidos por la Gaudium et Spes y la Laudato Si', motivan a un desafío urgente de la actividad de los seres humanos, para que unan a la familia humana con procesos creativos y que indiquen una trasformación, cuya búsqueda aplique a un desarrollo sostenible integral frente a la situación que a diario ocasiona el SARS- CoV-2 en la casa común. Para que oriente al ser humano de nuestro tiempo a valorar, plenamente, la vida que ha encontrado cuando vino al mundo, donde cada actividad sea un acto de dignidad humana, potenciada con la energía creativa, para la superación de situaciones que pueden llegar a convertirse, en un futuro inmediato, en costumbres direccionadas a un daño para con la vida. Lo que se busca es orientar una idea en la que el ser humano desarrolle un camino a la verdad, en un nuevo estilo de vida cuidando de este escenario por el cual hoy está atravesando:

Decía el padre Arrupe, ese gran Superior General de los jesuitas, que uno se debía proponer la meta de no dejar el mundo tal como lo encontró, en el mismo nivel que estaba cuando llego a la existencia. La gratitud obliga a la superación. (Llano Escobar, 2018, p. 3)

Así que, en acto de gratitud, valoremos las actividades que hoy se adelantan en favor de la vida, pero también seamos creativos y propongamos ideas, en cada contexto y cultura, que orienten una mejor calidad de la misma, tema que se tratará a continuación. 


\section{La creatividad en tiempo del SARS- CoV-2, como una actividad del ser humano}

El valor de la actividad del ser humano de hoy, corre el peligro de subordinar la dignidad humana; pues vive el miedo de que los logros científicos y tecnológicos, que si son desarrollados con un principio ético generan ganancia frente a la calidad de vida, pero, por otro lado, han dado espacio para que la actividad desarrollada, obra de sus propias manos y de su misma experiencia, se convierta en medio de destrucción, consecuencia de su actividad (Juan Pablo II, 1979). Así, tenemos la obligación de pensar y proponer qué es lo que queremos hacer, cuáles son nuestras opciones éticas. El poder que se nos ha dado sobre: la vida dentro de un orden natural, las generaciones futuras, sobre el medio ambiente, nos conduce a pensar en momentos cruciales de la historia de la humanidad, donde dejamos perder todo o ayudamos a conservar y fortalecer.

Ante esto, considero, que un trabajo enmarcado por la bioética personalista puede ser la base para una construcción, que pone sus valores plenamente humanos al servicio de una evolución racional, que aspira a la consecución de un paradigma dentro del valor de la actividad desarrollada por el ser humano como aporte al cuidado de la casa común. Abordaré la Bioética personalista, ya que, dentro de su propuesta permite hacer un análisis a esta investigación.

\section{La intención de la Bioética Personalista ante las situaciones generadas por el SARS- CoV-2}

Como un puente de reflexión, frente a lo que atañe a la situación generada por la COVID-19 en la búsqueda de una idea relacionada con la actividad creativa del ser humano, la Bioética Personalista, según indica José López Guzmán citando citando a Sgreccia:

... Ila Bioética, al igual que cualquier ética humana y social, tiene como puntos de referencia el valor fundamental de la vida humana; el valor trascendental de la persona; la concepción integral de la persona, que resulta como una síntesis unitaria de los valores físicos, psicológicos y espirituales; la relación de prioridad y complementariedad entre personas y sociedad, y una concepción personalista y "comunional" del amor conyugal' (p. 83)

Así, no se puede ser ajeno a reflexiones orientadas desde la lectura hecha por la mirada y pensamiento de hombres y mujeres conocedores de esta realidad, que sin olvidar la idea de Potter fundador de la bioética en los Estados Unidos (Llano Escobar, 2016, p. 3), son propuesta a países en vía de desarrollo, donde la preocupación será no solo los problemas éticos originados por el avance de la técnica y la medicina, sino por las realidades sociales que también originan problema al despliegue de la vida. Nos referimos a un proceso histórico de esas instancias teóricas y experienciales, que se vinculan el desarrollo progresivo del ser humano, pero necesitan del proceso de la educación para sumir con realeza el principio de la creatividad en cada actividad. 


\section{El desafío Bioético de la actividad humana frente al principio creatividad}

El desafío radica en que, en cada actividad realizada por los seres humanos, hoy se dé la importancia que merece la creatividad. Por la cual se pueden instaurar nuevos escenarios, que dentro de los parámetros éticos y morales, se den a conocer como creación de una cultura que ayuda a promover la vida que cada ser humano según el contexto que puede vivir y acoger. Al hacerlo con un lenguaje y acciones entendibles muy cercanas a las realidades que el ser humano hoy enfrenta. Así como a la gran preocupación por dar un rumbo diferente a lo que acontece hoy con el SARS- CoV-2, cuyo principio más central es el tema del valor de la vida, por el cual las agendas políticas públicas y distintos gremios de la sociedad ocupan sus tareas urgentes a desarrollar.

A partir de este postulado, que para esta investigación posee sus orígenes en el Concilio Vaticano Il y la Encíclica Laudato Si', se propone construir un nuevo saber orientador en el cual la actividad que cada ser humano desarrolla no se quede con los elementos básicos de construcción para la vida; sino que desde el ámbito educativo las agendas políticas se revistan de un interés particular, para que desde el ámbito profesional exista la posibilidad de ofrecer espacios creativos innovadores en las distintas ramas que hacen parte de la ciencia. Como también ayudar para que los distintos sectores de la humanidad, especialmente los más vulnerables de la sociedad acojan este espacio aconsejado por el Papa Francisco (2020) cuando dice: "Después de lo que hemos pasado este año, no deberíamos tener miedo de aventurarnos por nuevos caminos y proponer soluciones innovativas" (p. 12), que lleven a un cambio de paradigma que puede ser costumbre, interés o beneficio personal o destrucción de la vida en general como contribución a una búsqueda constante de la misma dignidad.

Así las cosas, dice la encíclica que: “...el exceso de estímulos nos desafía a intentar configurar una identidad integrada y feliz" (Francisco, 2015, art. 147), para que cada persona con su diario vivir, desarrolle alguna actividad que le proporcione alguna consecuencia positiva para la vida, lo más preocupante sería la no valorización de lo que el otro hace o intenta hacer dentro de su creatividad. Cuando esto sucede, el ser humano se siente desanimado, excluido, olvidado, rechazado dando origen a la cultura de ver solo lo malo. Inclinado solo a la espera de que alguien pueda hacer algo por él. De manera que para el escenario de vida, que hoy todos los seres humanos compartimos por causa de una pandemia, se están generando ambientes de espera de que alguien pueda hacer algo por cada uno, referido no solo a los temas de salud sino a lo que cobija el listado de derechos de deberes de cada ser humano.

Entonces, esta investigación se centra en la actividad que cada ser humano desarrolla, originada en el principio de creatividad, al cuidado de la vida desde lo que el hombre realiza en su diario vivir; es decir: que su actividad individual, familiar y social sea convertida en algo que le permita vivir bien y aportándole algo a los demás y al ambiente que lo rodea; su iniciativa creativa para con lo que se hace en su casa, en el camino, en los lugares de encuentro, en los vehículos, las fincas, los ambientes relacionados con la salud y el encuentro con más personas. Son estos algunos de los escenarios que permiten que el ser 
humano desempeñe alguna actividad y la pueda aplicar de la mejor manera, así lo dice Leonardo Boff y Mark Hathaway (2008):

... se sugiere que los seres humanos pueden desarrollar una sabiduría ecológica abriéndose a la alteridad de los demás seres y trabajando respetuosa y creativamente con ellos para buscar la sanación, la regeneración y la liberación integral de la comunidad de la Tierra. (p. 49)

Sugerencia que conduce a una mejor comprensión del objetivo propuesto en la creación de esta idea.

Después de este recorrido, se ha podido comprobar la riqueza del tema del principio de la creatividad dentro de la actividad de cada ser humano, como elemento valioso para una presentación integral de un nuevo paradigma de vida frente al suceso generado por la COVID-19, y la gran importancia que posee dentro del campo de la responsabilidad social en el mundo moderno. Entonces, se trata de poner de relieve el sentido práctico, como criterio metodológico en la vida cotidiana de cada ser humano, por su profunda importancia en el manejo de cada situación, que permite enlazar nuestro conocimiento histórico recapitulado en una herencia, doctrina, propuesta, visión y la actualidad de la responsabilidad que se tiene ante la vida, formulado por la Bioética. Pues su interés es hacer puentes entre saberes que comportan la supervivencia de la vida. En este trabajo, y en muchos otros, se convierte en la luz que ilumina el quehacer de los seres humanos.

Por tanto, el hombre y la mujer, según la teología, al ser partícipes del mundo creado y de la vida divina, han sido llamados a participar bajo el ámbito de la responsabilidad para con la vida, constituyendo un prototipo de educación y cultura para toda la humanidad. Por ende, la construcción de esta idea enmarcada en los valores humanos, enriquece la visión antropológica, social y espiritual del ser humano. Todos estos elementos se reúnen para dignificar más la vida haciendo que la historia tenga un sentido más pleno. Ya se ha evidenciado su importancia en las lecturas expuestas, lo cual permite dar comienzo a una nueva oportunidad de entender y comprender mejor la vida. A partir de lo anterior, la Iglesia y la Bioética no pueden permanecer indiferentes ante este gran acontecimiento del COVID-19. No solo será una ocasión para recordar el deseo de la Iglesia, sino que su alianza con la Bioética propone celebrar la propuesta realizada en la historia del mundo y del hombre: La "supervivencia" del mismo.

Finalmente, es pertinente tener presente la voz de "...madre y maestra de todos los pueblos..." (Juan XXIII, 1961, art. 262), de la Iglesia. Ella, hace memoria y anuncia su amor por la humanidad. No olvida las acciones de los seres humanos y sus adelantados trabajos, buscando como meta la salvación de los mismos. Nos sigue invitando a todos a realizar una seria lectura de la historia para que hoy, desde la ética de la vida, no se consideren las situaciones por las cuales atraviesa como aisladas, sino que se comprenda que están profundamente unidas, para educar, orientar, formar y encontrar soluciones positivas que esclarezcan aún más la verdad del misterio de la vida. Por eso, se hace importante que la educación ofrezca una idea a la actividad del ser humano que mejore el principio creativo, instrumento para una mejor ordenación de la vida humana. 


\section{La educación como un proceso de formación para la vida}

La educación es un acontecimiento que no se desconoce a lo largo de la historia de la humanidad, es un obrar del ayer, del hoy y de siempre, que como todo ha tenido sus cambios a su manera y el modo de poder entenderla, como el poder aplicarla a nuestro contexto actual. Ya que hoy nos enfrentamos a un mundo donde predomina el dominio de la palabra "veloz" o rápido, que hacen que la actividad del hombre no cumpla en muchos momentos con un objetivo trazado. Entonces no se hacen cada una de las actividades como verdaderamente debieran ser, por eso, "Ignorar que el hombre posee una naturaleza herida inclinada al mal, da lugar a graves errores en el dominio de la educación, de la política de la acción social y de las costumbres" (citado por Benedicto XVI, 2009, art. 34), que concluye originando un malestar individual, colectivo, el cual requiere una atención especialmente en el ámbito educativo que oriente el gusto y la veracidad de su quehacer convertidos en actividad, especialmente en la creatividad de ámbitos ordenados a la ética de la vida.

Por tanto, en el contexto del cuidado de la vida, como una tarea a desarrollar dice el Papa Francisco (2015), “...implica analizar el espacio donde transcurre la existencia de las personas" (art. 147), elemento constitutivo, para que la idea de que la educación sea una actividad que permita tener un nuevo concepto de vida, según el contexto donde orientar a cada ser humano hacia una mejor comprensión de una actividad. Como una esencia de la vida humana que debe ir acompañada de la creatividad y así lograr la cultura de la importancia de la actividad de cada persona, del conjunto de la familia y de la sociedad generando espacios de mejoramiento y fortalecimiento para con la vida, cuya meta se ha de ir cultivando día a día. Para esto el libro de Didáctica Integrativa y el Proceso de Aprendizaje nos dice que: "la educación es esencialmente un proceso de perfeccionamiento; es pasar de un estado a otro: de lo que se es a lo que se debe ser. La educación de la persona es el interés por mejorarla, por perfeccionarla" (Villalobos Pérez-Cortes, 2011, p. 33). Motivación frente al aporte que cada uno puede hacer para con el cuidado de la vida, portando un escenario que ha de ser motivo de superación, de un mejoramiento continuo desde el don o la cualidad que cada uno pose, ya que como dice el mismo Concilio Vaticano en la Declaración Gravissimum Educationis Momentum:

Todos los hombres, de cualquier raza, condición y edad, en cuanto participantes de la dignidad de la persona, tienen el derecho inalienable de una educación, que responda al propio fin, al propio carácter; al diferente sexo, y que sea conforme a la cultura y a las tradiciones patrias, y, al mismo tiempo, esté abierta a las relaciones fraternas con otros pueblos a fin de fomentar en la tierra la verdadera unidad y la paz. Mas la verdadera educación se propone la formación de la persona humana en orden a su fin último y al bien de las varias sociedades, de las que el hombre es miembro y de cuyas responsabilidades deberá tomar parte una vez llegado a la madurez. (Pablo Vl, 1965, art. 1)

Así, en continuidad a lo que nos propone el Concilio Vaticano ll y Laudato Si', el inicio de esta investigación, encontramos el fundamento en la bioética para proponer un trabajo educativo para nuestras comunidades de hoy que origine el valor de la actividad humana que nace de: 
...un interés renovado por comprender bien los contextos (lugares, sitios, escenarios) en los que se produce el aprendizaje, no solo por los contestos institucionales, sino, sobre todo por aquellos otros que se dan en otras agencias y contextos sociales como la familia, el trabajo o, en general, la 'vida cotidiana' (Rodríguez Illera, 2018, p. 261).

Para que de los mismos se pueda hacer eco a la creatividad de cada persona buscando la ayuda necesaria que permita desarrollar proyectos de vidas que enmarquen el sentido profundo por salvaguardar la misma. Así, podemos hablar de un desafío para construir escenarios desde la postura ofrecida por la bioética.

\section{Conclusiones}

Intentar hacer una apuesta al valor de la actividad humana, dentro de las distintas comunidades según su contexto y cultura, permite tener un acercamiento a algunos de los documentos, para crear un nuevo saber, que proponen como eje el principio de creatividad dentro de la actividad de los seres humanos en desarrollo de la vida, como elemento reparador a la situación originada por la COVID-19; pues el ser humano, de acuerdo a los principios morales y éticos, en su actividad cotidiana cuando incorpora el principio de creatividad contribuye a un desarrollo integral y al cuidado de la casa común.

El llamado de las distintas autoridades que rigen los gobiernos de los pueblos, indica una tarea ardua por el cuidado de la vida. Así, dentro del espacio de la corresponsabilidad, en la manera propuesta de cuidarnos, acudimos al objetivo propuesto por la Iglesia: evangelizar a los pueblos, para que ellos tengan vida en cada momento histórico que corresponde a nuestra estadía en este mundo; para que guiados por los elementos ofrecidos por la bioética personalista, se pueda hacer un aporte a lo que, la ciencia y la tecnología, han logrado para el bien de la vida; pero de una manera creativa donde se logre que la actividad innovadora de cada ser humano desde su condición de vida sea un principio para una mejor condición de la misma.

Así las cosas, animados por el Papa Francisco (2020) se nos dice que:

Una nueva era de solidaridad debe poner a todos los seres humanos en el mismo plano de la dignidad, cada uno asumiendo su propia responsabilidad y contribuyendo para que todos - uno mismo, los demás y las generaciones futuras puedan prosperar. (p. 15)

Se convierte en elemento de juicio que caracteriza los principios éticos y morarles para con la actividad que, aún desde el principio de la creatividad, genera ambientes consolidados en el proceso de vida que enmarcan miedos, incertidumbres y aislamientos sociales que necesitan un aporte para una condición de vida que hoy se siente herida y necesitada de apoyo para salvaguardarla. Por eso, otros estudios harán posible el mejoramiento de las condiciones de vida. 


\section{Referencias Bibliográficas}

Benedicto XVI. Vaticano II. Carta Encíclica Caritas in Veritate. 29 de junio de 2009. https://bit.ly/37Zr10a

Boff L. y Hathaway M. (2018). Ecología y teología de la naturaleza. Concilium: Revista internacional de teología, 378, 49-62. https://bit.ly/3rFZ4Tt

Biblia de Jerusalén. (1975). Bilbao: Desclee de Brouwer.

Pablo VI .Vaticano II. Gravissimum Educationis Momentum, sobre la educación cristiana. 28 de Octubre de 1965. https://bit.ly/3pAaqXh

Pablo VI .Vaticano II. Gaudium et Spes. 7 de diciembre de 1965. https://bit.ly/2Jv5I38

Díaz Abrahan, V. y Justel, N. (2019). Creatividad: una revisión descriptiva sobre nuestra capacidad de invención e innovación. CES Psicología, 12(3), 35-49. https://bit.ly/2KNi7L4

Francisco. Vaticano II. Carta Encíclica Laudato Si'. 24 de mayo de 2015. https://bit.ly/3nK9BuE

Francisco. (2020). La vida después de la pandemia. Ciudad del Vaticano: Editrice Vaticana. https://bit.ly/3rQuYNk

Instituto Nacional del Cáncer. (s.f.). SARS-CoV-2 [Def. 1]. En Diccionario del Cáncer. https://bit.ly/3823IZu

Juan Pablo II. Vaticano II. Redemtor Hominis. 4 de marzo de 1979. https://bit.ly/38I71yU

Juan XXIII. Vaticano II. Carta Encíclica, Mater et Magistra. 15 de mayo 1961. https://bit.ly/38LUDhs

López Guzmán, J. (2013). La bioética personalista en los planes de estudio universitarios. Cuadernos de Bioética, 24(80), 79-90. https://bit.ly/2WWOvNM

Llano Escobar, A. (2016). Volver a las fuentes [Editorial]. Selecciones de bioética, (23), 3. https://bit.ly/2MkF8FE

Llano Escobar, A. (2018). El bioeticista y la resiliencia [Editorial]. Selecciones de bioética, (26), 3. https://bit.ly/3hBIMaL

Rodríguez Illera, J. L. (2018). Educación informal, vida cotidiana y aprendizaje tácito. Teoría de la educación. Revista interuniversitaria, 30(1), 259-272. https://doi.org/10.14201/teoredu301259272

Villalobos Pérez-Cortes, E. M. (2011). Didáctica integrativa y el proceso de aprendizaje. México, DF: Trillas.

Para citar este artículo bajo Norma APA 7a ed.

Vergara Amaya, M. H. (2020). El principio de creatividad, en

tiempo de la COVID-19 en la actividad del ser humano.

Cuadernos de teología - Universidad Católica del Norte (En línea),

12, e4631, https://doi.org/10.22199/issn.0719-8175-2020-0009

Copyright del articulo: @2020 Mario Vergara

Este es un artículo de acceso abierto, bajo licencia Creative Commons BY 4.0. 